\title{
An unusual case of dysuria, pollakisuria, and eosinophilia: Questions
}

\author{
Fabian Eibensteiner $^{1}$ (D) Ursula Tonnhofer $^{2} \cdot$ Alexander Springer $^{2}$ (D) Hubert Kogler $^{3} \cdot$ Leila Ronceray $^{3}$. \\ Azadeh Hojreh $^{4}$. Christoph Aufricht ${ }^{1}$ (D) $\cdot$ Krisztina Rusai $^{1}$
}

Received: 27 April 2021 / Accepted: 7 May 2021 / Published online: 18 November 2021

(C) The Author(s) 2021

Keywords Eosinophilia $\cdot$ Cystitis $\cdot$ Cystic mass $\cdot$ Pediatric $\cdot$ Dysuria $\cdot$ Bladder wall thickening

\section{Case summary}

A 3-year-old boy was admitted to our pediatric urology department for further investigation of dysuria and pollakisuria. He was previously healthy and throve well. Macroscopic and microscopic urinary assessment did not reveal any pathologic features. A sonography of the boy's urinary tract revealed urinary bladder wall thickening (up to $2 \mathrm{~cm}$ ) with heterogenous echogenicity (Fig. 1). Further imaging with magnetic resonance imaging scans unraveled these heterogenous wall thickenings as polypus endoluminal concavities. The only other abnormal finding upon routine examination was peripheral eosinophilia (28\% of peripheral leukocytes and 2.47 $\times 10^{9} / \mathrm{L}$ absolute eosinophil count) in the boy's blood count. Eosinophilia is defined as the presence of higher absolute and relative counts of eosinophils in the

The answers to these questions can be found at https://doi.org/10.1007/ s00467-021-05130-8.

Krisztina Rusai

krisztina.heindl-rusai@meduniwien.ac.at

1 Division of Pediatric Nephrology and Gastroenterology, Comprehensive Center for Pediatrics, Medical University of Vienna, Waehringer Guertel 18-20, 1090 Vienna, Austria

2 Division of Pediatric Surgery, Comprehensive Center for Pediatrics, Medical University of Vienna, Waehringer Guertel 18-20, 1090 Vienna, Austria

3 Department of Pediatrics and Adolescent Medicine, St. Anna Children's Hospital, Medical University of Vienna, Waehringer Guertel 18-20, 1090 Vienna, Austria

4 Department of Biomedical Imaging and Image-guided Therapy, Medical University of Vienna, Waehringer Guertel 18-20, 1090 Vienna, Austria peripheral blood (> 5\% of peripheral leukocytes and $>$ $0.5 \times 10^{9} / \mathrm{L}$ absolute eosinophil count) [1]. Causes for eosinophilia are highly diverse and include primary (clonal) forms caused by hematologic neoplasms, and the more common secondary (reactive) forms due to allergic disorders (e.g., asthma and atopic dermatitis), parasitic and fungal infections, rheumatological diseases (e.g., systemic lupus erythematosus and vasculitis), respiratory diseases (e.g., eosinophilic pneumonia), other neoplasms (e.g., solid tumors and lymphomas), dermatologic disorders (e.g., Wells syndrome), disorders of immune regulation (e.g., hyper IgE syndrome), gastrointestinal disorders (e.g., eosinophilic esophagitis), and drugs [2]. Through clinical, serological, urinary, and fecal examinations, we could not identify any secondary causes for eosinophilia.

For the first and most important step to rule out bladder malignancy (i.e., rhabdomyosarcoma), and to either diagnose or rule out collagen vascular diseases, the boy underwent cystoscopy and subsequent biopsy of the polypus endoluminal concavities. Histologic analysis described an inflammatory eosinophilic-dominated infiltrate with no signs of malignant disease (Fig. 2). Symptomatic treatment with oxybutynin $(0.1 \mathrm{mg} / \mathrm{kg}$ three times a day) for the boy's dysuria and pollakisuria was initiated. Initially, the boy's symptoms were relieved, and the urinary bladder wall thickening declined after 1 month of treatment from 2 to $0.27 \mathrm{~cm}$. However, about 3 months after diagnosis, urinary bladder wall thickening increased to $0.5 \mathrm{~cm}$. The boy also experienced constipation, a common side effect of treatment with oxybutynin, and initial symptoms returned, with peripheral eosinophilia still at high levels (18\% of peripheral leukocytes and $1.9 \times 10^{9} / \mathrm{L}$ absolute eosinophil count). At the end of the fourth month of oxybutynin 


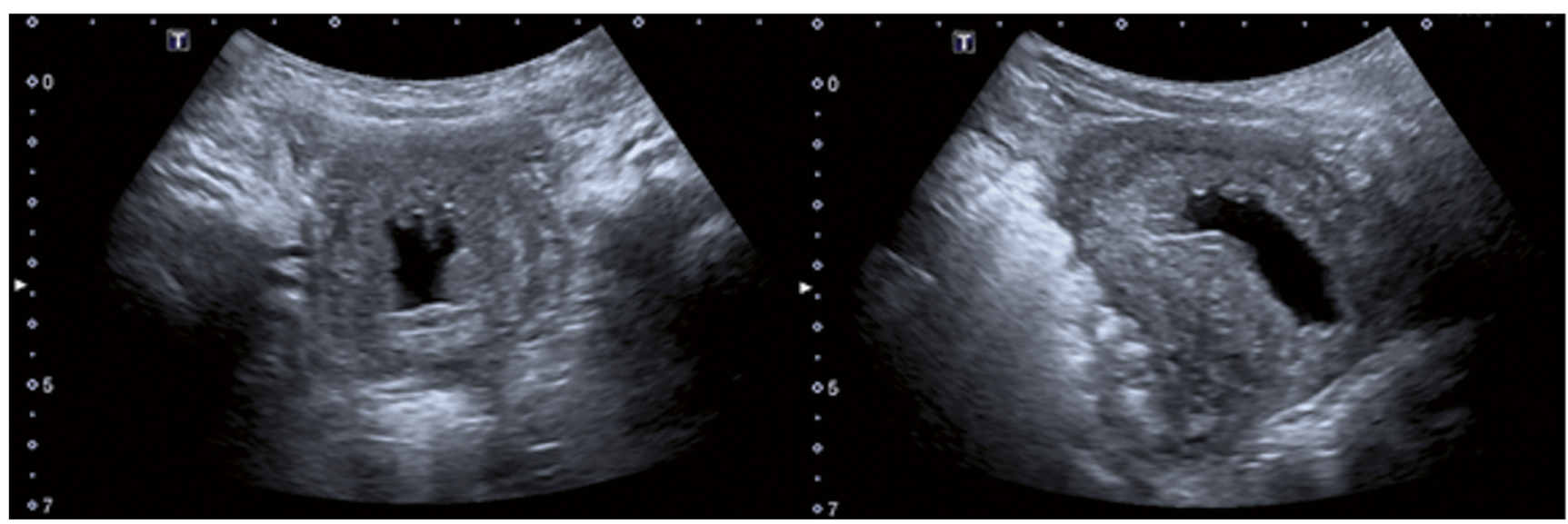

Fig. 1 Sonography of the urinary bladder axial (left) and sagittal (right) displaying urinary bladder wall thickening (up to $2 \mathrm{~cm}$ ) with heterogeneous echogenicity

treatment, bladder wall thickening increased up to $1.2 \mathrm{~cm}$ and the boy presented with weight loss of $2.3 \mathrm{~kg}$ over a period of 4 months, abdominal distention, and markedly decreased subcutaneous fat. Laboratory tests revealed hypoalbuminemia and deficiencies of iron, vitamin $\mathrm{D}$, and vitamin $\mathrm{A}$.

To rule out other reasons for the weight loss, we performed further analysis which revealed IgA antibodies against transglutaminase 2 of more than ten times the upper reference value $(>200 \mathrm{U} / \mathrm{mL}$ ) and positivity for endomysial antibodies (1:640). Together with positivity for endomysial antibodies (1:640) and the at-risk HLADQ2: A1*0505, B1*0202 genotype, the diagnosis of celiac disease was established [3].

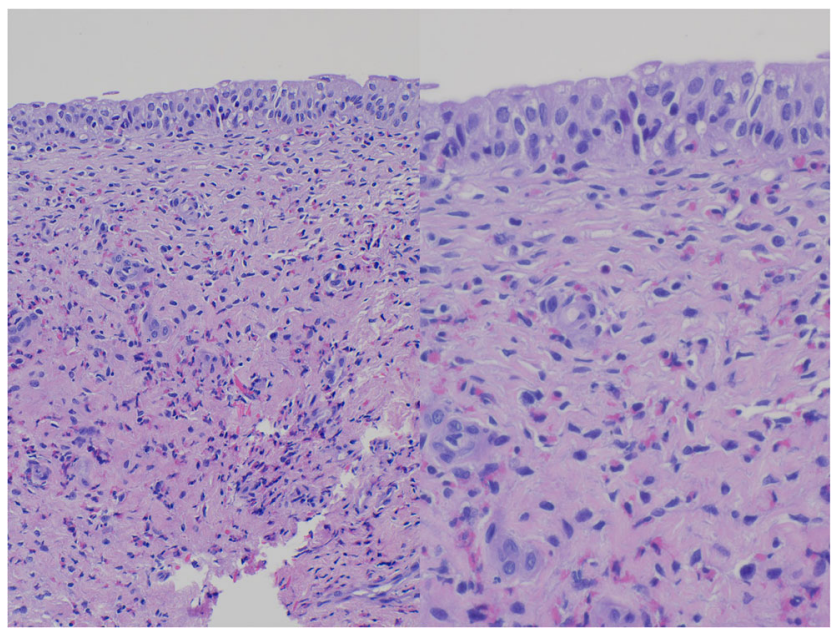

Fig. 2 Histological specimen (hematoxylin and eosin stain, $\times 200$ magnification [left] and $\times 400$ magnification [right]) of our patient displaying edematous subepithelial tissue with partly accentuated perivascular eosinophilic inflammatory infiltrates of varying density with partly reactive widened urothelial tissue

\section{Questions}

1. What is the diagnosis and what is its most likely etiology?

2. What further examinations should be performed?

3. What is the treatment for this disease?

Acknowledgements The authors are grateful to Dr. Anke Scharrer at the Clinical Institute of Pathology, Medical University of Vienna for providing information on the histologic specimen and to Dr. Andreas Vécsei at the Department of Pediatrics and Adolescent Medicine, St. Anna Children's Hospital, Medical University of Vienna, Vienna, Austria, for assistance with manuscript preparation.

Availability of data and material No data or additional material is made available.

Code availability No custom codes were used for this study.

Author contribution Dr. F Eibensteiner and Dr. K Rusai drafted the initial manuscript, reviewed, and revised the manuscript and take responsibility for the integrity and accuracy of the data presented. Critical revision of the manuscript for important intellectual content was done by Dr. U Tonnhofer, Dr. A Springer, Dr. A Hojreh, Dr. L Ronceray, Prof. Dr. Aufricht, and Dr. H Kogler. All authors approved the final manuscript as submitted.

Funding Open access funding provided by Medical University of Vienna.

\section{Declarations}

Ethics approval No approval needed in accordance with our local ethics committee.

Consent to participate Not applicable.

Consent for publication Consent for publication was given by each author as well as the patient's caregiver.

Conflict of interest The authors declare no competing interests. 
Open Access This article is licensed under a Creative Commons Attribution 4.0 International License, which permits use, sharing, adaptation, distribution and reproduction in any medium or format, as long as you give appropriate credit to the original author(s) and the source, provide a link to the Creative Commons licence, and indicate if changes were made. The images or other third party material in this article are included in the article's Creative Commons licence, unless indicated otherwise in a credit line to the material. If material is not included in the article's Creative Commons licence and your intended use is not permitted by statutory regulation or exceeds the permitted use, you will need to obtain permission directly from the copyright holder. To view a copy of this licence, visit http://creativecommons.org/licenses/by/4.0/.

\section{References}

1. Shomali W, Gotlib J (2019) World Health Organization-defined eosinophilic disorders: 2019 update on diagnosis, risk stratification, and management. Am J Hematol 94:1149-1167. https://doi.org/10. 1002/ajh.25617
2. Butt NM, Lambert J, Ali S, Beer PA, Cross NC, Duncombe A, Ewing J, Harrison CN, Knapper S, McLornan D, Mead AJ, Radia D, Bain BJ, British Committee for Standards in Haematology (2017) Guideline for the investigation and management of eosinophilia. Br J Haematol 176:553-572. https://doi.org/10.1111/bjh.14488

3. Husby S, Koletzko S, Korponay-Szabo IR, Mearin ML, Phillips A, Shamir R, Troncone R, Giersiepen K, Branski D, Catassi C, Lelgeman M, Maki M, Ribes-Koninckx C, Ventura A, Zimmer KP, ESPGHAN Gastroenterology Committee, European Society for Pediatric Gastroenterology, Hepatology, and Nutrition (2012) European Society for Pediatric Gastroenterology, Hepatology, and Nutrition guidelines for the diagnosis of coeliac disease. J Pediatr Gastroenterol Nutr 54:136-160. https://doi.org/10.1097/MPG. 0b013e31821a23d0

Publisher's note Springer Nature remains neutral with regard to jurisdictional claims in published maps and institutional affiliations. 